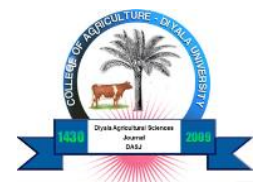

Web site: https://journal.djas.uodiyala.edu.iq/

ISSN: 2073-9524 (Print)

https://dx.doi.org/10.52951/dasj.21130110

ISSN: 2310-8746 (Online)

\title{
The Level of Awareness of Rural Woman in the Field of Home Health In Jam root Village in the Zummar Region/ Nineveh Province and Its Relationship with Some Variables
}

\author{
Abdel-Aziz Hamid Madhas ${ }^{1} \quad$ Maher Ibrahim Dawood ${ }^{2}$ \\ ${ }^{12}$ Department of Agricultural Extension and Technology Transfer / College of Agriculture \\ and Forestry / University of Mosul / Iraq \\ ${ }^{1}$ Corresponding author: abdalazizhm@uomosul.edu.iq
}

\begin{abstract}
The research aims to identify the level of awareness of rural women in field health of the homestead in each field of study fields, the health of kids, the health of animals, and health of commons in Zummar region/ Nineveh Province, identify the correlation between awareness of rural women and variables of study age, the educational level, job of husband, number of family and number of kids in the field of health in Zummar region/ Nineveh Province, the research includes all the rural women in research region whose their number 115 respondents, were taken random samples from 20 respondents pre-test its excluded from the original sample, it became final study sample of 95 respondents, the data was collected from the study respondents by a questionnaire, that is consisted of two parts: the first part includes the personal variables, the second part included the dependent variable that is rural women awareness, it consists of 29 items. Statistical program -Spss- used in the analysis of the data, the results shows, that the level of general rural women awareness /in Jamroot village, in the Zummar region was low. There are significant relationships between the level of general rural women awareness and some of the studied variables. The researcher gives some conclusions, generally, weak of awareness of rural women, in Jamroot village, in Zummar region in the field of the home health and he recommends increase their knowledge and information through providing themselves with health bulletins of the animal's health, children health, and even adults health.
\end{abstract}

Keywords: awareness, rural women, Zummar, home health.

\section{Introduction}

In recent years, given to rural development programs to achieve economic and social development. It requires direct efforts towards rural development and this qualifies them to be one of the fundamental factors in rural development (World Bank, 2008; Jaradat, A.A. 2006)

. The rural woman is considered an important part of the society and has got an active role in rural development and agricultural production, as well as her role in the house and her kid's health, (Arab Organization for Agricultural Development, 1997) importance of preparing food and the field (Hammed and Dhoha, 2020).

The rural woman has several roles among them is her house, her husband, and administration of her children, as far as agriculture. (Arab Organization for Agricultural

\section{Dates:}

Received: 26 March $2021 \quad$ Accepted 11 May 2021

Published: 30 June 2021 
Development, 2009), and her different roles in the family as took the decisions in her family (World Bank, 2008).

Women in Arab countries represent more than half of the rural community and participate in the majority of agricultural work, whether at home or in the field, the participation of rural women in development processes should be on an equal footing with men after the progress of societies is measured by the extent of the progress and development of rural women (AlLeela and Asma, 2012).

The extent of their contribution to development processes of all kinds so as not to leave an idle, marginalized, or dependent energy on the other half (Rogers, 2003). Women in Iraq play an important role in the real development process, as the rational use of all human and material resources. And that the obstacles that stand in their way are the obstacles that face the societies of the third world in general (Jiggins and Samantha, 2003), the Arab world in particular. Among those obstacles: psychological and social obstacles that do not deny the role of women in affirming some of their aspects, much of the development literature indicates that extension organizations in various fields related to the role of women as a productive workforce and as a housewife and wife (Seevers et al, 2007).

The roles of the rural woman beside her brother of man are responsible for saving food in their houses; and upbringing the children; they are the most important element of supporting the household, in family decision making, besides their active support in the production (Harbi, 1997).

The rural women work in agricultural production, they represent the majority of the agricultural labor force in their countries because they produce the bulk of the locally consumed food (Al-Leela and Asma, 2011). This qualifies them to be one of the fundamental factors in achieving economic development in rural families (World Bank, 2008). Women played an important role in the development process. Genuine development is the good utilization of the entire human and material resources and the obstacles, which obstruct their way are, as the same as those facing the societies of the third world in general (AL-Lela and Asma, 2011), In view of the considerable importance of the women, and scarcity or absence of the studies, which dealt with the rural women in awareness of her health, her kid's health and her house, especially in the shade of the coronavirus pandemic, the study comes to answer the following questions:

1- What is the level of awareness of rural women in Jamroot village in the field of home health in the Zummar region/ Nineveh Province?

2- What is the relationship between awareness of rural women and variables of study age, the educational level, number of the members of the family, and number of children in the field of health of the home in Zummar region/ Nineveh

Province?

The Objectives of the study:

1- Identify the level of awareness of rural women in field health in the Zummar region/ Nineveh Province. 
2- Identify the level of awareness of rural women in field health of the homestead in each field of study fields, the health of kids, the health of animals, and health of commons in Zummar region/ Nineveh Province.

3- knowledge of correlation ship between awareness of rural women and variables of study age, the educational level, job of husband, number of families, and number of kids in the field of health in Zummar region/ Nineveh Province.

The importance of the research:

The importance of the study lies in the work of rural women in their houses, and its relation with the commonalty health of their family. This importance in the knowledge of the educational level for rural women in their houses, this importance in the knowledge of the health of members of the family and number of children.

Statistical hypotheses:

To achieve the objectives, the statistical hypotheses, put as follows:

There is no significant relationship between the level of health awareness of the rural women and each field of study fields, the health of kids, the health of animals, and the health of commons.

Definitions of Action Research:

Health of Commons: this means, the health of people in the house, general health, and of foods for rural women in the area of zummar.

Awareness of health:

This means that, all the information and knowledges of rural women in the field of homestead health and their children's health.

Jamroot:

This is one of the villages in the zummar region/ nineveh province, its large number from of woman.

Previous studies: There is no previous studies which similar to this research.

\section{Materials and Methods}

Region of the research: Zummar region/Nineveh, was chosen to be the place of the research, wherein more rural women were needed of Healthy awareness in all life aspects.

The approach of the research: the descriptive approach was used in this research since it is suitable for applied research and it provides reality (Al-Rashidi, 2002).

The Population of the research:-the research population includes all rural women in Jamroot village from Zummar region/Nineveh 115 women were taken from it for pre-test sample with size 20 respondents, it becomes the final sample size of 95 respondents.

Data collection:- the collection of data includes a questionnaire that is used as a tool from respondents, which consists of two parts:- The first part includes independent variables such as, age, educational level, husband job, number of families, number of children.

The second part includes the dependent variables the healthy awareness, consist of 29 items which were taken from books and resources which related to the topic of the research, addition to the amendments of experts specialized in the research subject and others information of rural woman in Zummar region. front for each item, quadruple scale, for mensuration of dependent variable, this is highest awareness, medium awareness, least awareness, no awareness, and the items, divided of three fields, include each field 10 
items, as follows:- 10 items for health field of children, 10 items for health field of animals and 9 items for health field of commons. As shown in table 1.

Table 1. showing the number of the fields and the items of the health awareness

\begin{tabular}{|c|c|c|c|}
\hline $\begin{array}{l}\mathrm{N} \\
\mathrm{O}\end{array}$ & $\begin{array}{l}\text { Number } \\
\text { of fields }\end{array}$ & $\begin{array}{l}\text { Number } \\
\text { of items }\end{array}$ & items minutiae \\
\hline & & & 1- Cleaning the house from time to time. \\
\hline & & & 2-Disinfect the house with disinfectants every day. \\
\hline & & & Cleaning home appliances from time to time. 3- \\
\hline & & & $\begin{array}{l}\text { 4- Sterilization of family members' clothes before using } \\
\text { them. }\end{array}$ \\
\hline & health & & 5-Building animal housing away from family housing. \\
\hline 1 & $\begin{array}{l}\text { field of } \\
\text { children }\end{array}$ & 10 items & 6-Putting garbage in special places away from people. \\
\hline & & & Take safety measures when using oil heaters. 7- \\
\hline & & & $\begin{array}{l}\text { 8-Extinguishing the oil heater outside the room after } \\
\text { using it. }\end{array}$ \\
\hline & & & Allow the sun's rays to enter the house to sterilize it. 9- \\
\hline & & & $\begin{array}{l}\begin{array}{l}\text { 10-Opening doors and windows every day for } \\
\text { ventilation. }\end{array} \\
\end{array}$ \\
\hline & & & Sterilize vegetables and fruits before eating them. 11- \\
\hline & & & Get rid of rotting and shoddy fruits and vegetables. 12- \\
\hline & & & 13- Keeping fruits and vegetables in the refrigerator. \\
\hline & & & Fruits and vegetables are not left exposed at home. 14- \\
\hline & & & Throwing food waste in special places. $15-$ \\
\hline 2 & $\begin{array}{l}\text { health } \\
\text { field of }\end{array}$ & 10 items & $\begin{array}{l}\text { Wash and sterilize hands before and after eating foods. } \\
16 \text { - }\end{array}$ \\
\hline & animals & & Clean utensils well before and after cooking food. 17- \\
\hline & & & 18-Disinfect drinking glasses with hot water before use. \\
\hline & & & 19-Sterilize the milk utensils well before milking. \\
\hline & & & 20-Boil the milk well before eating it. \\
\hline & & & Ensure the validity of the cans. 21- \\
\hline & & & Do not use expired cans. 22- \\
\hline & health & & Not leaving eating utensils uncovered..23- \\
\hline & field of & & \\
\hline & common & & Disinfect the house from dust and insects 24- \\
\hline & S & & Spray insecticide to get rid of harmful insects $25-$ \\
\hline & & & 26- Take preventive measures when spraying pesticides. \\
\hline & & & Using electrocution for flies and mosquitoes. \\
\hline
\end{tabular}




\begin{tabular}{|l|l|l|l|l|}
\hline & & & $27-$ \\
\hline \hline & & & Use an electric mosquito fumigator 28- & \\
\hline \hline & & & $\begin{array}{l}\text { 29-Take out family members when spraying the } \\
\text { insecticide. }\end{array}$ \\
\hline \hline & & & & \\
\hline \hline Total & 30 items & & \\
\hline
\end{tabular}

Characteristics of tool Measurement:- the questionnaire is completed in the last form, for knowing of face validity of research tool, the tool that is presented for a panel of experts in agricultural extension department and medicinal plants experts, were taken their suggestions and their opinions in it, Tool was treated and found that is reliability.

To be sure from its reliability, the questionnaires sent to 20 respondents, and after receiving the tool from respondents and their answers, they complete it in the last form, it was treated by Alpha-Cronbach's method Arifaj and et al (1999), so the reliability coefficient 0.85 was considered acceptable, this indicates the reliability of the scale since it reached the value of the reliability coefficient more than 0.70 is acceptable Murad and Amin, 2002-260. Finally, The questionnaire becomes ready for collecting data.

Mensuration of research variables: Mensuration of independent variables as follows:-

Measurement of independent research variables: the independent variables are measured as follows:

Age; It was measured by giving one degree per year.

Educational level; It was measured in seven levels, in each level, a value is given numbers as follows: 1 read and write 2, primary 3 secondary 4 , a graduate of institute 5, graduation of college BSc 6, Master's Degree 7.

The number of the family: It was tested by giving one degree for each person of the family. The number of children: It was measured by giving one degree for each child.

Measurement of the dependent variable as follows:- this is measuring by a quadruple scale, it was, higher awareness, medium awareness, little awareness, no awareness, it is given numeric values $4,3,2,1$, respectively, became total health awareness degrees between 29116 degree for all the fields.

Collection of the data: the final data that is collected from 95 respondents in mentions the name of the village in the region of study. They answered all the questions of tool contents, and the data became ready for Analysis.

Statistical facilities; after the entrance of data in Excel program, it was analyzed using spss program -Package Social Sciences Statistical- Al-Hiti (2006), and some of other statistical as; the Average, standard deviation and frequencies.

\section{Results and Discussion}

1 - The first objective is to identify the level of Table 2 shows the highest percentage of respondents which reached $68.42 \%$. Therefore, the level of health awareness of the rural women of Zummar /region, they have in awareness of rural women in the field of health of the homestead in Zummar region/ Nineveh Province.

The results showed the numerical values which are indicated in the level of health awareness of rural woman in Zummar region/ Nineveh Province, was average 21,6, standard deviation 2,7, was the actual range between 18-56, was the highest value was 56 and the lowest value was 18 , on this basis, The respondents were divided into three categories, as showed in Table 2 
Table 2. Distribution of respondents according to home health awareness of rural women in Zummar

\begin{tabular}{|l|l|l|l|l|l|}
\hline Classes & Degree Classe & Number & $\%$ & Arithmetic mean & Notes \\
\hline \hline Low & $18-31$ & 65 & 68.42 & 22 & SD 2.7 \\
\hline \hline Medium & $32-45$ & 20 & 22.10 & 34 & Mean 21.6 \\
\hline \hline High & 46 -and more & 10 & 10.52 & 45 & \\
\hline \hline Total & & 95 & $100 \%$ & & \\
\hline
\end{tabular}

Table 2. shows the highest percentage of respondents which reached $68.42 \%$. Therefore, the level of health awareness of the rural women of Zummar /region, they have little information in this field.

2- The second objective is the identification of the level of awareness of rural women in the field of health of the homestead in each field, health of children, the health of animals, and health of commons, in Zummar region/ Nineveh Province.

1-The First field health of children: the results showed the numerical values which are indicated in the level of health awareness of rural woman in Zummar region/ Nineveh Province health of children was average 16,5, standard deviation 4,1, was the actual range between 9-34, was the highest value was 34 and the lowest value was 9, on this basis, The respondents were divided into three categories, as showed in Table 3.

Table 3. Distribution of respondents according to awareness in-field health of children of rural women

\begin{tabular}{|l|l|l|l|l|l|}
\hline Classes & Degree Classe & Number & $\%$ & Arithmetic mean & Notes \\
\hline \hline Low & $9-16$ & 60 & 63.15 & 15 & SD 4.1 \\
\hline \hline Medium & $17-24$ & 22 & 24.21 & 19 & Mean 16.5 \\
\hline \hline High & $25-34$ & 13 & 13.68 & 28 & \\
\hline \hline Total & & 95 & $100 \%$ & & \\
\hline
\end{tabular}

Table 3 showed the highest percentage of respondents with a percentage of $63.15 \%$. Therefore, the level of awareness of the women in the health of children in the Zummar region is very low, since they have little information in this field.

The second field, health of family:- The results showed the numerical values which are indicated in the level of health awareness of rural woman in Zummar region/ Nineveh Province in this field was average 13.5, standard deviation 3.3, was the actual range between 8-32, was the highest value was 33 and the lowest value was 8 , on this basis, The respondents were divided into three categories, as showed in Table 4.

Table 4. Distribution of respondents according to awareness in-field health of the family of rural women

\begin{tabular}{|l|l|l|l|l|l|}
\hline Classes & Degree Classe & Number & $\%$ & Arithmetic mean & Notes \\
\hline \hline Low & $8-17$ & 56 & 58.94 & 14 & SD 13.5 \\
\hline \hline Medium & $18-23$ & 17 & 17.89 & 19 & Mean 3.3 \\
\hline
\end{tabular}




\begin{tabular}{|l|l|l|l|l|l|}
\hline High & $24-32$ & 22 & 23.15 & 27 & \\
\hline \hline Total & & 95 & $100 \%$ & & \\
\hline
\end{tabular}

Table 4 gave the highest percentage of respondents, with a percentage of $59.94 \%$. Therefore, the level of awareness of the women in the health of children in Zummar is little.

3- The third field is the health of the general: The results show the level of awareness of rural women in Zummar / Nineveh in-field health of the general which ranged between 426 with an average of 11.7 and a standard deviation of 3,8 on a quadruple theoretical scale that ranged between $4-26$ The respondents were divided into three categories by using the theoretical range, as showed in Table 5.

Table 5. Distribution of respondents according to awareness in-field health of the general of rural women in Zummar

\begin{tabular}{|l|l|l|l|l|l|}
\hline Classes & Degree Classe & Number & $\%$ & Arithmetic mean & Notes \\
\hline \hline Low & $4-10$ & 55 & 57.89 & 12 & SD 3.8 \\
\hline \hline Medium & $11-17$ & 20 & 22.10 & 17 & Mean 11.7 \\
\hline \hline High & 18 and more & 20 & 22.10 & 25 & \\
\hline \hline Total & & 95 & $100 \%$ & & \\
\hline
\end{tabular}

Table 5 showed the highest percentage of respondents, which was in the low category, with a percentage of $57.89 \%$. Therefore, the level of awareness of the women in the health of general in Zummar is very low, because they have very little information in healthy of general.

3 - The third objective: knowledge of correlationship between awareness of rural women and variables of studyage, the educational level, job of husband, number of family and number of kids in field of health in Zummar region/ Nineveh Province .

1-Age: The ages of the respondents were limited between 18 - 60 years, with an average of 45 years, and a standard deviation 5.2.

Table 6. Distribution of respondents according to the age

\begin{tabular}{|l|l|l|l|l|l|}
\hline Classes & Degree Classe & Number & $\%$ & Arithmetic mean & Notes \\
\hline \hline Low & $18-31$ & 44 & 46.31 & 12 & SD 5.2 \\
\hline \hline Medium & $32-45$ & 32 & 33.68 & 17 & Mean 45 \\
\hline \hline High & $46-60$ & 19 & 20 & 25 & \\
\hline \hline Total & & 95 & $100 \%$ & & \\
\hline
\end{tabular}

The table above, show that the highest awareness of the respondents was between the ages of 18 - 31, where they accounted for $46.31 \%$ percent of participants, and to find the relationship between the level of awareness and age, person's relationship was used, and for testing the relationship, the p. value 0.634 is used and which amounted more than 0.05. This suggests that the relationship between the variable of awareness and the variable of age is not significant, so we accept the statistical hypothesis, which says that the ages of the respondents have little information on homestead health awareness. 
2- The educational level: in the research, the level of education of the participant's region was limited between reading and writing - high degree and the six distributed categories according to the educational level, as shown in Table 5.

Table 7. Distribution of respondents according to educational level

\begin{tabular}{|l|l|l|l|l|}
\hline Classes & Number & Percentage & p. value & $\infty$ \\
\hline \hline Read and write & 37 & 38.94 & & \\
\hline \hline Primary & 31 & 32.63 & & \\
\hline Secondary & 20 & 21.5 & & \\
\hline \hline Diploma & 7 & 7.63 & 0.256 & 0.05 \\
\hline BSc. Degree & 0 & 0 & & \\
\hline \hline high degree & 0 & 0 & & \\
\hline Total & 95 & $100 \%$ & & \\
\hline
\end{tabular}

Table 7 shows that the highest awareness of the respondents was in Category read and write where they reached $38.94 \%$, the reason is that they may have information in homestead health, more than other levels.

To find the relationship between the level of awareness and the educational level, the researcher used the spearman correlation, whose value was 0,256, and to test the incorporeally in the relation, used p.value, which reached 0,031 that is less than 0.05 .

This indicates if there is a relationship between the awareness and educational level, so we reject the statistical hypothesis and accept the alternative one which says there is a relationship of incorporeal between the level of awareness and educational level because the rural woman has several information in a healthy culture.

3- The Number of the family: The number of members of families were limiting between 1 6 individual, with an average of 3 , and a standard deviation 1,1 . The respondents were distributed to three categories according to the range, as shown in Table 8.

Table 8. Distribution of respondents according to number of families

\begin{tabular}{|l|l|l|l|l|}
\hline Categories & Number & Percentage & p.value & $\infty$ \\
\hline Low 1-2 & 13 & 13.68 & & \\
\hline \hline Medium 3-4 & 37 & 38.94 & & \multirow{2}{*}{0.41} \\
\hline High 5-6 & 45 & 47.36 & & \\
\hline \hline Total & 95 & $100 \%$ & & \\
\hline
\end{tabular}

Table 8 found that the highest level of awareness was in the category of $5-6$ whose percentage reached $47.36 \%$ and the category of $1-2$ is the last one, and its Percentage is $15 \%$, this happened because of increasing the number of individuals in family information in homestead health. The researcher has used the Pearson correlation coefficient, whose value is 0,242 , And for the test of the relationship incorporeally between the two variables, used p.value, which reached 0.41 which was less than 0.05 , indicates that the relationship between the awareness and number of the family is incorporeally, so we reject the statistical hypothesis and accept the alternative hypothesis which states there is a significant relationship between the level of awareness and the number of families.

4- The number of kids: It is found that the number of children ranged between $0-4$, and the respondents were divided into three categories, as explained in Table 8. 
Table 9. Distribution of respondents according to the number of kids

\begin{tabular}{|l|l|l|l|l|}
\hline Categories & Number & Percentage & p.value & $\infty$ \\
\hline \hline Low 0- & 15 & 15.78 & & \\
\hline \hline Medium 2-3 & 26 & 27.36 & 0,352 & \multirow{2}{*}{0,05} \\
\hline \hline High 4- above & 54 & 56.84 & & \\
\hline \hline Total & 95 & $100 \%$ & & \\
\hline
\end{tabular}

It found that the more awareness where percentage reached $56.84 \%$. to find the relationship between the level of awareness and awareness of cultivation, Pearson is used which its value 0,352 , and to test the significance relationship reached 0,047 which is less than 0.05 , and this indicates that the significant relationship between the variable of the number of kids and the variable of awareness was the significant relationship, so we reject the statistical hypothesis and accept the alternative. this is because the respondents have many skid so that, their awareness of hers kids health must be less of them.

\section{Conclusions}

Generally, rural women in Zummar in field of the homestead health have little information, the awareness of rural women in the field of health of kids is more than their awareness in general and animal health. The awareness for rural women in the field of animals is more than their awareness of the health of the general. Also, This study recommends the rural women in the Zummar region increase their knowledge and information through providing themselves with health bulletins of the animal's health, children health, and even adults health by lectures and seminars on in-field health of humans and animals, in Zummar and by using training courses in the field of the homestead health.

\section{Conflict of interest}

The authors declare that they have no competing interests.

\section{Acknowledgments}

The authors are very grateful to the University of Diyala and Diyala Agricultural Sciences journal, which helped to improve the quality of this work.

\section{References}

Al-Abbasi, Amel Fadel Khalil. 2017. Wareness of livestock keepers in some regions of Nineveh Province about common diseases between humans and animals and its relationship to some variables Tikrit University Journal For Agricultural Sciences. 17 (4): 310-322.

Al-Leela, Zeki H. and Asma, Z. Al-Hafidh. 2011. Level of Rural Women Knowledge in Domain Food Industries and its relation with Some Variables In the villages of Shrikhan and Qubba/Nineva Province, College of Agriculture and Forestry, Master thesis, Mesopotamia Agriculture Journal. 39 (4) 225-237.

Al-Leela, Zeki H. and Asma, Z. Al-Hafidh. 2012. Level of rural women knowledge in domain family care and its relation with some variables field study in the two villages of al_shrikhan and qubba/nineva Province, college of agriculture and forestry,university of Mosul, Mesopotamia Agriculture Journal. 40 (4) 301-313. 
Al-Rashidi, Bashir Saleh. 2002. Curricula for Educational Research, College of Education, Kuwait University, 1st edition, Dar Al-Kutub Al-Haditha.

Arab Organization for Agricultural Development. 2009. The Organization Supports Activates Arabic Rural Woman. Jop Paper. Production Projective Accomplished for Arabic Woman 2010-2012, Khartoum Sudan, p. 3.

Arab Organization for Agricultural Development. 1997. Project National Project Document for Active Role Rural Woman in Rural Development, Khartoum Sudan, p.20

Arifaj, Sami, Khaled Musleh, 1999. Measurement and Evaluation, 4th Edition, Majdalawi House For Printing And Publishing, Amman, Jordan.

Hameed,Talal Saeed . Dhoha mostafa abd al faraje. 2020. Cows breeder's awareness of the transitional diseases that affect the farm animals in rabiaa district, Nineveh Province, Iraq, Plant Archives . 20 (1): 3455-3460.

Harbi, Miryam Ali Salim 1997 .A Sociological Study of Women Participation in Egyptian Rural; Area ,College of Agriculture, Al-Azher University.

Jaradat, A.A. 2006. Agriculture in Iraq . food Agriculture Environment .Vol.2 Danielastehlik : Australia, women unite, report .

Jiggins, J .J and R.K. Samantha . 2003. Improving women Farmer's , FAO.

Mahfouz. 2009. Basic statistical analysis using Spss, 2nd edition, Wael House for Publishing \& Distribution, Amman, Jordan.

Murad, S. A., and A. A. Suleiman. 2002. Tests and Standards In Psychological And Educational Sciences, Steps For Their Preparation And Characteristics, 1st Edition, Dar Al-Kitab Al-Hadith, Kuwait.

Rogers, E.M. 2003. Diffusion of Innovations, 5th Edition, the Free Press, New York.USA.

Seevers, B., G. Donna and C. Nkki. 2007. Education through cooperation ,and Edition , published by Curriculum Materials Service, The Ohio State University.

World bank. 2008. gender in agriculture, agriculture and rural development. 